emphasis upon traffic regulation and zoning quite as much as upon the development of new highways, the officials of the Three A's are turning toward the solution of traffic problems. It is recognized today that the next ten years will see the construction of super-highways, and the physical alteration of parts of many cities to provide traffic avenues for the new methods of transportation which have come to stay, and the American Automobile Association is doing its share in preparing the public mind to accept the developments that are bound to come, even though great municipal expenditures are involved.

But of immediate concern, and recognized importance, is the question of uniform traffic regulations and signals in cities. The solution of the problem is made more complex by the variety of types of cities and the geographical differences. But a start must be made and the A. A. A. has joined with other important transportation agencies in supporting financially and by appropriate co-operative activity a national conference on street and highway safety called by the Secretary of Commerce. This conference, divided into various sections of experts, has been at work for weeks and it is expected that before the end of the year the conclusions of this important conference will be placed before the public as a starting point in the universal adoption of constructive traffic rules and practices.

There are over $16,000,000$ motor cars in the United States and half of them are owned in communities of 5,000 or more population. Nearly one-fourth of the motor vehicles of the country are owned in the cities of 100,000 population or above. Hundreds of thousands of motor trucks are engaged in interstate traffic. You can travel half way across the United States on motor bus lines and this phase of motor development has just begun.

However much the American Automobile Association may have accomplished in the past, its responsibility has now become the greater because its activities helped materially to create this new commercial and pleasurable manifestation of the present century and its vast resources and its far-flung contacts and the ability it possesses within its ranks can and will be used for the solution of those motor problems which bulk so hugely upon the horizon of the average American citizen.

\title{
The Place of the University in Good Roads and Automobile Transportation
}

By Arthur H. Blanchard

Professor of Highway Engineering and Highway Transport, University of Michigan, and President, National Highway Traffic Association

$\mathrm{T}$ WE present status of education for highway engineering throughout the United States is comparable to the standing of the work of the highway engineer, in the mind of the American lay public, and, to a greater or less extent, in the opinion of the engineering profession. The nonrecognition by legislators of the necessity of placing the control of the administration, construction and maintenance of highways in the hands of well-educated and efficiently-trained highway engineers, is reflected by the expressed attitude of many educators in the allotment of the small amount of time which is devoted 
to highway engineering in our universities.

The waste of millions of dollars annually in the United States will continue until the profession of highway engineering is placed on the same basis as structural, hydraulic, sanitary and kindred branches of civil engineering. England, France and other European countries have seen the light. As a result, efficient highway engineers are retained in office, organizations are perfected, methods of construction and maintenance suitable for local conditions are employed and as a consequence the public funds are wisely and economically expended.

It is advisable to call attention to the character of the positions which are being filled today by high way engineers. Such positions are found in national, state, county, municipal and town engineering departments, contractors' organizations and the engineering and research departments of companies manufacturing road machinery and materials used in highway engineering.

\section{Necessary Educational Ground WORK}

In order that the civil engineer in embryo should enter on his life work at graduation with as general a knowledge of the field of highway engineering as of other branches of civil engineering, it is necessary that considerable attention should have been given by him to the following subjects: (1) A study of the historical development of highways, exemplifying the inter-relationship between social progress and the improvement of public traveled ways; (2) preliminary investigations, including traffic investigations and highway transport surveys, to determine the amount and character of future traffic; (3) surveying and mapping, peculiar to highway engineering; (4) the theory and design of highways; and (5) a consid- eration of materials used in and the methods of construction and maintenance of the many classes of roads and pavements which exist, which study would include drainage and foundations. Furthermore, such important subjects as street cleaning and snow removal; the relationship of the construction of car tracks and pipe systems, sidewalks, bridges and culverts to highways; and, finally, the comparison of the essential characteristics of roads and pavements and a consideration of economics, administration and legislation as applied to highway problems should be considered.

It is obvious that to recommend that, as an integral part of all civil engineering curricula, a specific amount of time should be devoted to the study of highway engineering, would be as unjustifiable as the practice of many laymen in seeking for a panacea in the form of one type of road or pavement to satisfy all traffic and local conditions. It is advocated, however, that as much time should be devoted to highway engineering as is now assigned to hydraulic or sanitary engineering, or to railroad engineering. If this plan is adopted, at least three semester hours would be assigned to highway engineering, as a requirement for all civil engineering students.

Educators throughout the United States should seek to elevate the profession of highway engineering in America to the plane of the National Department of Roads and Bridges of France and to provide an opportunity for men engaged in highway work to obtain advanced instruction and training under favorable conditions. The heads of national, state, county and municipal highway departments should be broadly educated, thoroughly trained and experienced specialists in highway engineering and efficient exec- 
utives. They should be able to discuss publicly and to solve economically the fundamental problems of highway economics, administration, construction and maintenance. Such men should have a broad educational training in such humanities as English, history, economics, philosophy, political and social science. They should also be well grounded in the fundamentals of pure and applied science which underlie highway engineering and the several branches of civil engineering which are utilized in highway work. After a man has secured his fundamental education in engineering and has had a certain amount of practical experience in highway work, the opportune time has arrived for securing professional equipment through the medium of graduate courses in highway engineering.

\section{What Highway Transport Educa- TION Should InClude}

What is included in highway transport education? The author conceives that highway transport education should cover the fundamentals of the science, art, economics and business of the transportation of passengers and commodities over highways. Courses in this field will be taken by men looking forward to the profession of highway transport engineering, the motorvehicle industry, and the businesses of traffic management and highway transport.

In the opinion of some, highway transport may not be considered as belonging to the field of technical training and education. On sober thought, however, it will be seen that this branch of knowledge comes well within the classic definition of engineering embodied in the Royal Charter of the Institution of Civil Engineers of Great Britain, which, in part, is as follows:

The art of directing the great sources of power in nature for the use and conven- ience of man, as the means of production and of traffic in states, both for external and internal trade.

From the standpoint of highway transport business, courses in this field will be taken by men who desire to equip themselves efficiently for the positions of business administrators, dealers, salesmen and advertisers in the motor-vehicle industry, and executives, operators, traffic managers, motor-truck fleet managers, and dispatchers in the commercial field of highway transport, and in the closely related fields of railway and waterway transport.

What is the demand for highway transport engineers and men equipped for highway transport business? In May, 1920, the First National Conference on Highway Engineering and Highway Transport Education held in Washington, D. C., unanimously adopted the conclusion that 4,000 men should be trained in highway transport each year in universities for the positions heretofore enumerated.

\section{Results of Inadequate Training}

Many have misinterpreted the meaning of this conclusion. Emphasis should be placed on the words "should be trained." The representative committee framing this conclusion had in mind the economic and efficient utilization of highway transport in the transportation system of the United States.

What is the present situation in regard to the demand for highway transport engineers and men trained in the business of highway transport?

Many highway departments are not properly designing the highways for even immediate future traffic, because their personnel does not include men who have had the proper training in highway transport to have a vision and adequate background which will enable 
them to diagnose the probable development of traffic on a given highway. Or, in other words, to make a highway transport survey, the prerequisite of economic highway design, which embodies all investigations in the field and office which are necessary to efficiently estimate the probable amount, character and effects of the future traffic which will use a given highway during the lives of its several component parts.

Motor-truck manufacturers' organizations are in a chaotic condition, from the standpoint of the proper utilization of men trained in highway transport. Why? In general, they have followed in the obliterated footsteps of companies manufacturing highway machinery and materials. The latter companies originally established departments which were advertised to give unbiased consulting service to their customers.

What was the result? In the first place, it was found impracticable to divorce unbiased opinion from the commercial interests of the organization represented and soon prospective customers began to realize this selfevident fact. Second, disastrous conflict arose between the highway transport engineering department and the sales organization, a natural result to anyone familiar with the inter-relationship existing between the activities of such departments.

In the near future the motor-truck manufacturers of this country will see the light and follow in the footsteps of the closely related companies which have already passed through the transition stage. Concretely stated, the sales organizations of motor truck, tractor and trailer companies should be composed of men trained in the fundamentals of highway transport and the efficient use of the equipment manufactured by the company which they represent.
Failures of highway transport enterprises are occurring every day, due to a lack of knowledge of the fundamentals of the economics, science and art of highway transport. It is reported that ninety per cent of all highway transport companies doing business with New York City as a center fail within three years after entering this field. While fifty per cent may fail, due to cut-throat competition by fly-by-night companies, it is conservatively estimated that at least fifty per cent fail because of lack of knowledge of the A B C's of efficient highway transport business methods, cost accounting, management, and the operation and maintenance of equipment.

\section{Highway Transport Education}

We find a satisfactory status relative to the development of highway transport education in the universities throughout the United States. In some institutions, the logical development occurs by the men having charge of highway engineering courses giving courses in the related field of highway transport. In other institutions, such courses are offered by the department of economics or business administration.

If these departments are to teach highway transport efficiently, the instructors must have a knowledge of the fundamentals of the economics and science of highway engineering and practical highway transport. It is expected that notable developments will take place along these lines, especially when authoritative texts are available. We have a development, in the main, of undergraduate instruction in the fundamentals of highway transport.

\section{Graduate Courses}

The practicing engineer may secure advanced knowledge pertaining to modern practice in his speciality by the 
utilization of one or more of the following agencies: (a) technical literature; (b) meetings and transactions of technical societies; (c) graduate engineering courses in technical institutions.

American educational institutions offer the following channels which are open to men who desire to equip themselves for the profession of engineering.

1. A bachelor of arts, bachelor of philosophy, or bachelor of science collegiate course with electives in engineering.

2. A four-year course in general engineering.

3. A four-year course in a special field of engineering.

4. A graduate engineering course requiring a baccalaureate degree and a total attendance in educational institutions of from five to six years.

5. Graduate engineering courses after having followed out one of the educational lines outlined above.

By a judicious utilization of educational facilities, the acquisition of an educational training for any given branch of the engineering profession maybeattained by several combinations of the courses previously mentioned.

As used in this paper, graduate courses for practicing engineers refer to advanced specialized courses designed primarily for men who have taken a first degree in art, science, or engineering; who have acquired a knowledge of fundamental principles upon which such advanced courses are based; and who have had a certain amount of practical experience in engineering work.

Based on an experience with graduate courses for practicing engineers extending over a period of fourteen years, it has been found that the following classes of men are interested in such courses:

(a) Graduates of four-year bach- elor of science courses in general engineering and graduates in nontechnical courses who wish to equip themselves for a special field of engineering work.

(b) Graduates in civil, chemical, electrical, mechanical, and mining engineering courses who come in contact with problems or fields of work, with reference to which they desire detailed information based on modern engineering experience.

(c) Non-graduates who may be engineers, chemists, contractors, manufacturers, or others interested in some special branch of engineering and who have acquired a sufficient knowledge of the fundamental principles to enable them to carry on advanced work satisfactorily.

As a definite indication of the demand for advanced courses in special fields of engineering will be cited the fact that during one year one hundred and ten men, whose average age was twenty-seven years, enrolled in the graduate professional short-period courses in highway engineering and highway transport at the University of Michigan.

The conclusion has been reached by experienced engineers that, if graduate courses are to meet satisfactorily the demands of the profession, the following conditions should be fulfilled:

1. The courses must be given by specialists who are acknowledged experts.

2. The courses must be given under such conditions that it will be practicable for practicing engineers and others engaged in engineering work to take advantage of the opportunities offered.

3. The graduate work must be broadly administered so that the courses of instruction are open to any mature man, provided he can satisfy the prerequisites for the given course or courses which he desires to take.

4. The content of the courses must 
cover detailed information pertaining to the most recent developments of modern practice.

5. The methods of presentation of the subject matter of the course must be adaptable to the class of men enrolled.
6. Ample facilities must be available for conducting research work in laboratories, libraries and in the field, where every phase of the special field of engineering covered by the graduate courses may be investigated. 